\title{
'A GOOD RELATIONSHIP AND GOOD COMMUNICATION ARE NOT SUFFICIENT FOR PATIENT-CENTRED CARE'
}

Koula Asimakopoulou is a psychologist and a Senior Lecturer at the Dental Institute, King's College London. Her research interests are in behaviour change in oral health settings, supporting the dental team in the provision of patientcentred care, and in particular the understanding of and communication of risk information to increase patient adherence.

\section{What attracted you to psychology?}

I was interested in finding out why people do what they do. Also, I felt that if I went into psychology I would end up with a job that saw me 'help people'. However, it was only after my first couple of weeks of psychology training, which involved measuring reaction times and action potentials, that I realised that psychology was in fact a lab-based science and there would not be much 'helping people' involved!

\section{How did you end up involved in dentistry?}

My leap into dentistry was accidental, though I am now really grateful that this accident happened! My $\mathrm{PhD}$ training was in understanding neuropsychological functioning in people with type 2 diabetes. I was interested in looking at how patients with diabetes could be best supported to change their diet, take up exercise and check their blood glucose regularly.

I became interested in understanding how fear campaigns and the risk of further disease might sometimes be used inappropriately by the health system to engender fear in a futile attempt to scare diabetes patients into changing their diet and increasing their physical activity etc. Dentistry is linked to diabetes as the latter is known to cause problems with oral health and undermine people's efforts to look after their teeth, so when a lecturer position came up at King's Dental Institute I felt very lucky to be appointed to it.

\section{'The GDC is telling dentists \\ What is the result of using a fear-based approach?} to be patientcentred but it has not yet made it entirely clear to them how to do this...'
A fear-based approach gets people worried about the problem and opens up two responses: to tackle the fearful situation or to ignore it. Where the fear is substantial and the problem is seen by the patient as one they cannot solve, the evidence tells us that people tend to run away from it. As to why dentists and doctors alike may use fear campaigns, this is an interesting one. Common sense would argue that if you warn people of dire consequences they should change their behaviour to avoid them but it does not work like that does it? If it did no one would smoke, over-eat or take drugs!

\section{What are you working on at the moment?}

My work now is entirely focused on oral health. At the moment we have several projects going; the primary one is to help dentists use risk language appropriately in order to support behaviour change in oral health patients. We have a randomised control trial (RCT) about to start which is going to assess whether giving people individualised information about their risk of periodontal disease using Previser software works better than routine care, especially when it comes in a package of behavioural science techniques aiming to 'switch on' change in patients.

I am also interested in patientcentred care and supporting dentists to practise in ways that are personcentred. At the moment the GDC is

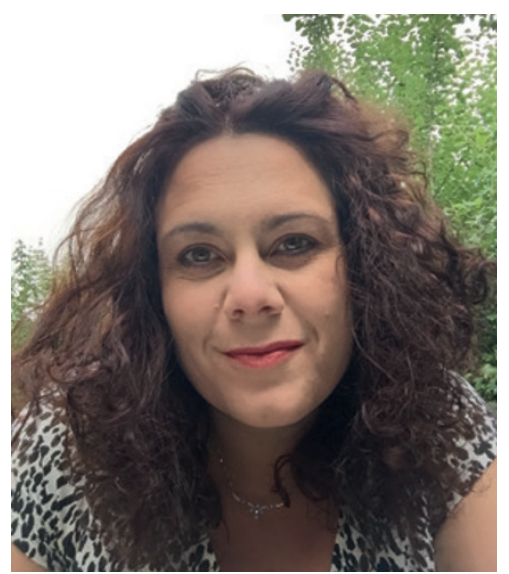

expecting dentists to be patient-centred but it has not yet made it entirely clear to them how to do this. So, our team here is working on understanding patient-centred care in dental settings, finding the areas that colleagues need support in and developing interventions to enable them to take patient-centred care into practice.

What are the most important elements of patient-centred care (PCC)?

Obviously, good communication and an appropriate, respectful relationship between dentist and patient are at the heart of PCC. However, although necessary, I do not feel that good communication and a good relationship are themselves sufficient for PCC. My colleague, Dr Sasha Scambler and I have developed a hierarchy of PCC that argues that 'being nice' to patients is basic common sense and a rule of humanity but is not in itself enough to be called PCC. PCC goes beyond this and it is about giving patients information and choice - true choice - over all the available options to do with treatment (including those options the dentist does not favour themselves) and then supporting the patient in deciding what action to take.

\section{What do you think are the major challenges facing dentistry in the UK?}

Dentistry is changing all the time and I think dental teams have a hard job to do to keep up with the changes whilst providing 
evidence-based care. I worry that dental teams are so busy providing clinical care that sometimes they are pushed to keep on top of the evidence base.

\section{How do you solve the problem of time constraints for dentists who must provide clinical care and keep on top of the evidence base?}

This is a tricky one. I think if dentists saw keeping up with the evidence-base as a necessary condition of providing excellent care, rather than an adjunct to it, they would find ways to incorporate it into their daily practice. So take for example dental fear. A dentist can spend a long time attempting to manage a dentally anxious person through 'common sense' or they can spend a day reading Professor Newton's latest research on how to manage a dentally anxious person on the basis of the behavioural evidence (ie in tried and tested ways), thereby saving themselves hours of stress, patient complaints and so on. It does not make sense not to make time to read the evidence really. It is like saying: 'I would like to make my car work more efficiently but I do not have the time to read the manual that tells me exactly what to do.'

\section{Why don't patients do as we ask them to do?}

Because they are normal human beings, of course, and non-adherence with healthcare instructions seems to be part and parcel of the human psyche! But seriously, there are many psychological views as to why people do not do what dentists ask them to do, all of which look at things like how willing, able and supported the patient feels in carrying out instructions. Most people tend to erroneously think that it's about knowledge, ie if you tell patients how to floss they will surely do it. Sadly, it is not as simple as that. There are behavioural techniques dentists can use to enhance the chance that patients will follow through with dental advice, all of which rest on the patient having some knowledge about what we ask them to do. The evidence base now is very clear that knowledge per se is not enough to change behaviour in our patients. Psychologists can help with this aspect of the consultation and our social and behavioural sciences team at KCL have a lot of expertise in this domain.

\section{How do psychologists help with changing the behaviour?}

Well, it depends on the behaviour (and probably on the psychologist). Dr Blánaid Daly and I recently completed supervising a PhD study where we helped Kuwaiti pregnant women to brush and floss more. With the student, Dr Suad Alkhamis, we designed a RCT that was culturally-sensitive, that is, it took into account local women's rather unusual and quite inaccurate beliefs about oral health during pregnancy, and looked to see whether their oral health (as measured clinically by plaque and gingival indices) would change after this intervention.

The intervention tested giving simple, culturally appropriate dental health education compared with more complex psychological interventions that helped the women plan their brushing and flossing, and change their beliefs about these behaviours. We found that women's plaque and gingival index scores improved following the intervention, alongside their beliefs which were now more in line with the evidencebase on the necessity to brush and floss while pregnant.

\section{What are the most common mistakes made when communicating risk and obtaining consent?}

Trying to scare people by telling them their risk is really high is often the most common mistake made. This coupled with the fact that most people, including clinicians, have difficulty understanding probabilities (on which risks are obviously based) makes risk communication a rather fraught exercise. Obtaining consent is equally interesting - obtaining consent and obtaining 'informed' consent are two rather separate processes in my mind and some people are better at one rather than the other.
'Trying to scare people by telling them their risk is really high is often the most common mistake made.'

\section{What are your top tips to dentists for improving communication with patients?}

I only have one - look at the evidence base and communicate science-based advice.

\section{Any tips on how dentists can make the science of dentistry more understandable for lay patients?}

Patients, in my experience, with the amount of information available at their fingertips nowadays are often in a good position to understand science anyway. So no special measures are necessary really other than the obvious of ensuring that jargon is kept to a minimum and where it is used clinicians should ensure that patient understanding is checked. People normally understand ideas they have an interest in; given that most patients have an interest in their own health (or they would not be seeing the dentist in the first place), all dentists need is knowledge of the evidence-base, and the time and aptitude to pass the knowledge on.

\section{What are you most proud of?}

My two children - who are often ignored so that I might stare at a laptop. They are only 5 and 9, but both going on 19 !

\section{If you had to live and work anywhere in the world (outside the UK) where would you go?}

Somewhere cold where some English or Spanish is spoken and there is good skiing in the winter.

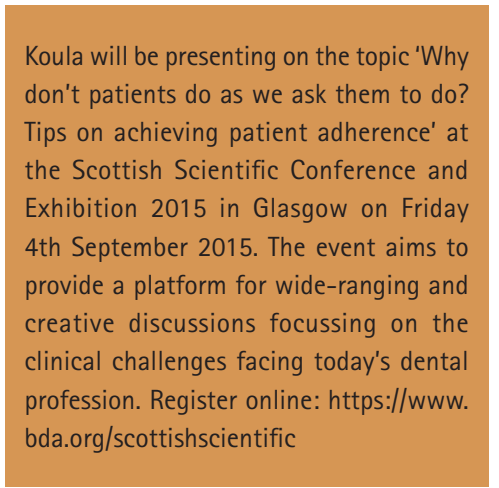

